\title{
Synthesis of Ordered Polymer Micro and Nanostructures Via Porous Templates
}

\author{
R. Palacios ${ }^{1}$, P. Formentín ${ }^{1}$, A. Santos ${ }^{1}$, T. Trifonov ${ }^{2}$, J. Pallarés ${ }^{1}$, R. Alcubilla ${ }^{2}$ and L. F. Marsal ${ }^{1}$ \\ ${ }^{1}$ Departament d'Enginyeria Electrònica, Elèctrica i Automàtica, Universitat Rovira i Virgili, Av. Paissos \\ Catalans 26, 43007 Tarragona, Spain. \\ ${ }^{2}$ Departament d'Enginyeria Electrònica, Universitat Politècnica de Catalunya, Edifici C4, Campus Nord, Jordi \\ Girona 1-3, 08034 Barcelona, Spain. \\ E-mail: lluis.marsal@urv.cat
}

\begin{abstract}
The deposition of specific materials into ordered pores arranged in a regular lattice allows the fabrication of ordered fiber arrays. Polymer micro- and nanofibers using macroporous silicon and nanoporous alumina templates were fabricated employing a vacuum infiltration method for Poly(methyl methacrylate) (PMMA) structures or a melt-assisted template wetting into the pores for Poly(3-hexylthiophene) (P3HT) structures. We have studied how the aspect ratio of the micro- and nanopores and the kind of polymer influence the structures fabrication.
\end{abstract}

\section{INTRODUCTION}

In recent years, the fabrication of microstructures and nanostructures has attracted great interest [1-3]. The deposition of specific materials, such as polymers and non-linear materials, into porous templates allows tailoring new structures. Macroporous silicon and nanoporous alumina are attractive candidates for use as templates in order to obtain ordered structures [4-6]. These micro- and nanostructures have a wide range of potential applications, such as cellular engineering, solar cells and photonic crystals [7-10]. Herein, we present the fabrication of micro- and nanopillars made of Poly(methyl) methacrylate (PMMA) and Poly(3hexylthipophene) (P3HT) by infiltration into the pores of macroporous silicon and self-ordered nanoporous alumina.

\section{EXPERIMENTAL}

Macroporous silicon templates were prepared by lightassisted electrochemical etching [11]. The starting material was n-type silicon with a resistivity of $2-3 \Omega \mathrm{cm}$. The front side of the wafers was patterned with inverted pyramid shaped pits by oxidation, photolithography, and subsequent tetramethyl ammonium hydroxide (TMAH) etching. These inverted pyramids act as nucleation sites for the ordered pore growth. The wafers were incorporated in an electrochemical etching cell containing a $5 \mathrm{wt} \%$ aqueous solution of $\mathrm{HF}$ acid at low temperature. The quality and size of the pores were controlled by a computerized feedback mechanism to maintain a constant pore diameter. Samples with a pore depth between $22 \mu \mathrm{m}$ and $7.5 \mu \mathrm{m}$ and pore diameter value of $2 \mu \mathrm{m}$ were fabricated. In order to see the effect of the opening pore, free-standing silicon membranes were prepared as well, when after pore growth the back side of the wafer was etched until the pores were opened. In this case porous silicon membranes with between $150 \mu \mathrm{m}$ and $40 \mu \mathrm{m}$ of pore depth were obtained.

In order to prepare nanoporous alumina, high purity 99.999\% aluminum (Al) foils from Goodfellow Cambridge Ltd. were used as substrates. First, the foils were cleaned in an ultrasonic bath of acetone and then were annealed in nitrogen at $400^{\circ} \mathrm{C}$ for 3 hours. The following step was electropolishing of $\mathrm{Al}$ foils in 4:1 mixture of ethanol and $\mathrm{HClO}_{4}$. The potenciostatic regime of $20 \mathrm{~V}$ was applied for 2 minutes to obtain a smooth mirror-finished surface followed by a rinsed with pure ethanol and deinozed water. From this aluminum, alumina templates were made by simple or hard anodization.

Aluminum samples were put through a 2-step anodizing process in order to create self-ordered porous alumina on the aluminum surface [12]. The first anodization was performed in $0.3 \mathrm{M}$ oxalic acid $\left(\mathrm{C}_{2} \mathrm{O}_{4} \mathrm{H}_{2}\right)$ solution at constant voltage and temperature [21]. After removing porous alumina by a wet chemical etching in a mixture of $0.4 \mathrm{M}$ phosphoric acid $\left(\mathrm{H}_{3} \mathrm{PO}_{4}\right)$ and $0.2 \mathrm{M}$ chromic acid $\left(\mathrm{H}_{2} \mathrm{CrO}_{4}\right)$ at $70^{\circ} \mathrm{C}$, a second anodization was performed under different voltages and times. Pore-widening treatment was carried out in $5 \mathrm{wt} \%$ phosphoric acid at $35^{\circ} \mathrm{C}$. The depth and pore diameter were controlled by changing the voltages and times on each anodization and the pore-widening treatment times. Samples with pore depths between $600 \mathrm{~nm}$ and $1.3 \mu \mathrm{m}$ and pore diameter between $50 \mathrm{~nm}$ and $250 \mathrm{~nm}$ were prepared.

Poly(methyl methacrylate) (PMMA, Mw $=120,000$ purchased from Sigma-Aldrich) and Poly(3-hexylthiophene) (P3HT, melting point $238{ }^{\circ} \mathrm{C}$, Mw $~ 17500 \mathrm{~g}$ mol-1, 99.995\% regioregularity, purchased from Sigma-Aldrich) were selected as polymeric materials. PMMA can be used in various kinds of applications due to its versatility and its optical properties. On the other hand, the thiophene family member P3HT is one of the most promising conjugated polymers for polymer-based photovoltaic cells.

PMMA pillars were fabricated by vacuum infiltration of a solution of the polymer in toluene. The technique was an infiltration by putting a drop of the solution on top of the 
sample located under vacuum. The samples were heated at $110^{\circ} \mathrm{C}$ during $3 \mathrm{~h}$.

P3HT pillars were fabricated using the melt-assisted wetting method. Briefly, $50 \mathrm{ml}$ of a $20 \mathrm{mg} \mathrm{mL}^{-1}$ solution of P3HT in tetrahydrofurane (THF) was drop cast on a glass coverslip and left to dry in order to form a thick P3HT layer. It was soaked in a $3 \mathrm{M}$ aqueous solution of sodium hydroxide $(\mathrm{NaOH})$ for 10 $\mathrm{s}$, rinsed with deionised water. The P3HT layer was peeled off the glass support and placed onto the template. The sample was annealed at $250^{\circ} \mathrm{C}$ for $30 \mathrm{~min}$, in order to melt inject the polymer into the porous template, and was then slowly cooled to room temperature.

Polymer micropillars were obtained by an immersion into $40 \mathrm{wt} \%$ aqueous solution of potassium hydroxide $(\mathrm{KOH})$ at $40^{\circ} \mathrm{C}$ in order to remove the silicon template.

Polymer nanopillars were immersed into a solution containing 6.8 gr of copper (II) chloride $\left(\mathrm{CuCl}_{2}\right), 200 \mathrm{ml}$ of $37 \%$ hydrochloric acid $(\mathrm{HCl})$ and $200 \mathrm{ml}$ of deionised water, in order to remove the remaining aluminum. Polymer nanopillars were obtained by the selective dissolution of the alumina template in a $1 \mathrm{M}$ sodium hydroxide $(\mathrm{NaOH})$ aqueous solution at room temperature for $20 \mathrm{~min}$.

All the samples were inspected in environmental scanning electron microscopy (ESEM-FEI Quanta 600) at an accelerating voltage of $20-30 \mathrm{kV}$. In order to avoid deformations upon heating during ESEM observation, a thin gold layer was deposited on the polymer nanopillars.

\section{RESULTS}

Figure 1 shows the diagram in sequence of the formation of polymer pillars from the top surface of the macroporous silicon or nanoporous alumina templates. Microtubes are obtained when the template employed is a silicon membrane. The interior of the pore has not been completely filled by the polymer (fig. 1a). However, if the template is open only at one end, such as macroporous silicon and nanoporous alumina, a complete filling of the pores occurs, obtaining polymer microfibers as replicas of the template (fig. 1b) [3-13].

Membranes with a pore diameter of $3 \mu \mathrm{m}$ and pore depths of $150 \mu \mathrm{m}$ and $40 \mu \mathrm{m}$, and substrates open only at one end with a pore diameter value of $2 \mu \mathrm{m}$ and various pore depth values from $22 \mu \mathrm{m}$ to $7.5 \mu \mathrm{m}$ prepared according to procedures described previously, were employed in this work. Figure 2 shows these macroporous silicon templates.

Figure 3 shows the top side of the self-ordered nanoporous alumina employed as template, which was prepared by using a two-step anodization process according to the procedures described previously. Simple anodizations were made with 50 $\mathrm{V}$ at $15^{\circ} \mathrm{C}$ in each anodization, first of them was for $2 \mathrm{~h}$ and the second one was different for each sample in order to obtain pore depths between $1.3 \mu \mathrm{m}$ and $600 \mathrm{~nm}$. Diameter between $50 \mathrm{~nm}$ and $65 \mathrm{~nm}$ were obtained by change of the porewidening treatment time. Hard anodizations were made with $170 \mathrm{~V}$ at $\quad-5^{\circ} \mathrm{C}$ in each anodization, first one for $30 \mathrm{~min}$ and second one was different for each sample in order to obtain pore depths between $1.3 \mu \mathrm{m}$ and $900 \mathrm{~nm}$. Diameters about 250 $\mathrm{nm}$ were obtained with a pore-widening treatment time of 30 $\min$.

Figure 4 shows PMMA microtubes with diameters about 3 $\mu \mathrm{m}$ and a pore depth of $150 \mu \mathrm{m}$ and PMMA microfibers with diameter about $2 \mu \mathrm{m}$ and pore depth of $12 \mu \mathrm{m}$ obtained from macroporous silicon. Figure 6 shows PMMA nanofibers with diameters about $50 \mathrm{~nm}$ and pore depths about $1.3 \mu \mathrm{m}$ and 600 $\mathrm{nm}$ respectively obtained from self-ordered nanoporous alumina.

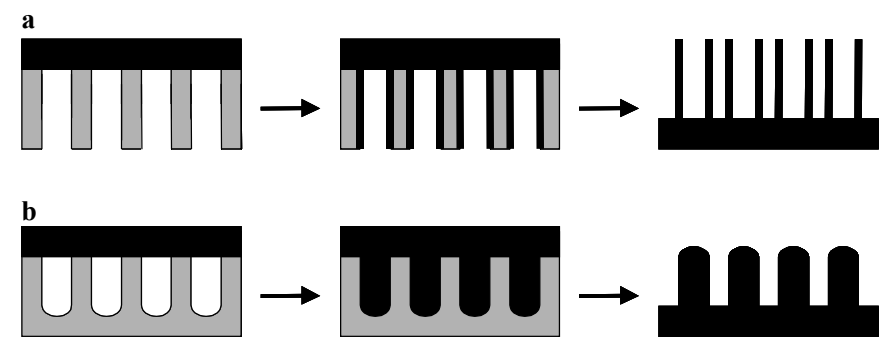

Fig. 1. Schematic diagram of melt-assisted wetting process using silicon membranes (a) and silicon substrates open only at one end or nanoporous alumina (b). Polymer $\square$ Template $\square$.
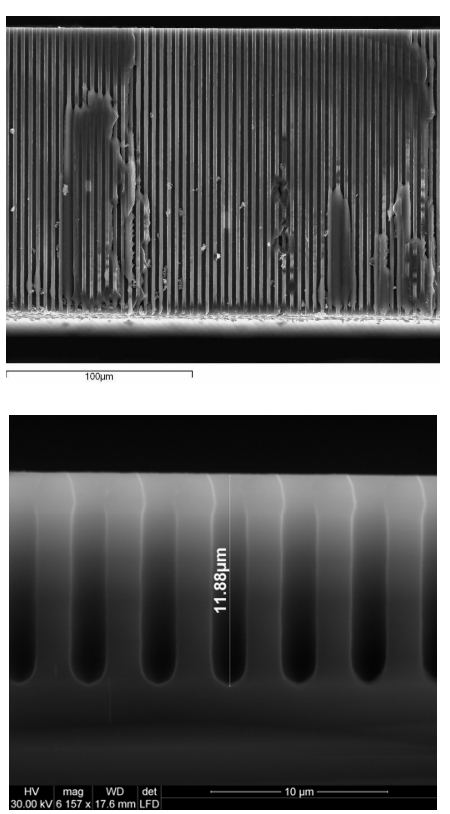

Fig. 2. Environmental Scanning Electron Microscopy (ESEM) images of macroporous silicon membranes and macroporous silicon open only at one end respectively.

Figure 6 shows P3HT microtubes with diameters about 2 $\mu \mathrm{m}$ and pore depth of $40 \mu \mathrm{m}$ and P3HT microfibers with diameter about $2 \mu \mathrm{m}$ and pore depth of $22 \mu \mathrm{m}$ obtained from macroporous silicon. Figure 7 shows PMMA nanofibers with diameter about $250 \mathrm{~nm}$ and pore depths about $1.3 \mu \mathrm{m}$ and 900 $\mathrm{nm}$ respectively obtained from self-ordered nanoporous alumina. 
Proceedings of the 2009 Spanish Conference on Electron Devices - Feb 11-13, 2009. Santiago de Compostela, Spain.

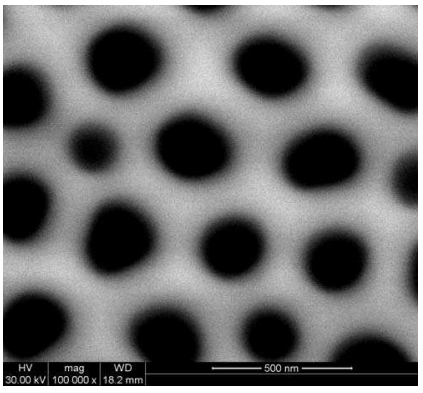

Fig. 3. Environmental Scanning Electron Microscopy (ESEM) images of self-ordered nanoporous alumina prepared by hard anodization.
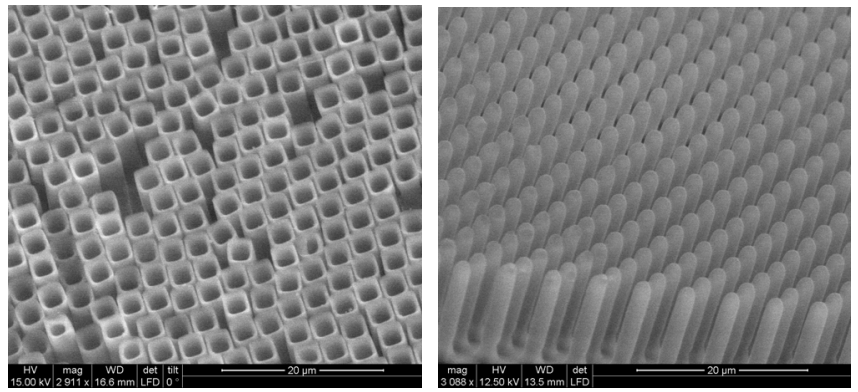

Fig. 4. Environmental Scanning Electron Microscopy (ESEM) images of PMMA microstubes and microfibers respectively after removing template.
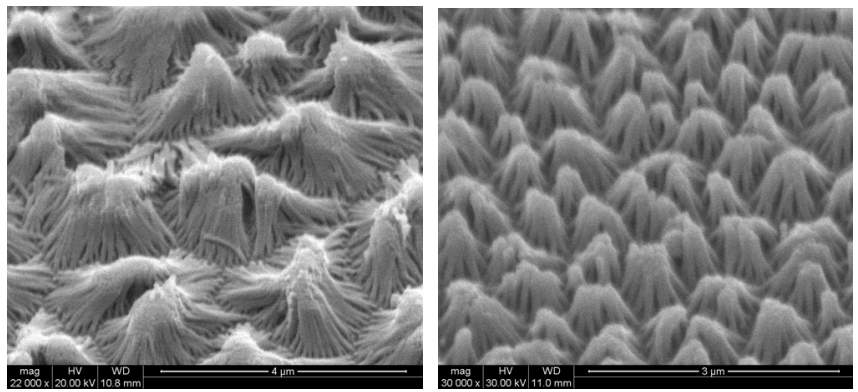

Fig. 5. Environmental Scanning Electron Microscopy (ESEM) images of PMMA nanofibers after removing template.

\section{CONCLUSION}

In this work, we have studied how the type of template and polymer influence the micro- and nanostructures fabricated. Results show that free-standing micropillars can be produce using silicon template with a pore depth less than about $15 \mu \mathrm{m}$. Microtubes are congregated in any polymer due to their length and diameter. Nanopillars with these pore depths and diameters start to congregate. Further work is needed in order to develop the potential applications of polymeric ordered structures.

\section{ACKNOWLEDGMENT}

This work is supported by Spanish Ministry of Education and Science (MEC) under grant number TEC-2006-06531 and HOPE CSD2007-00007 (Consolider-Ingenio 2010).
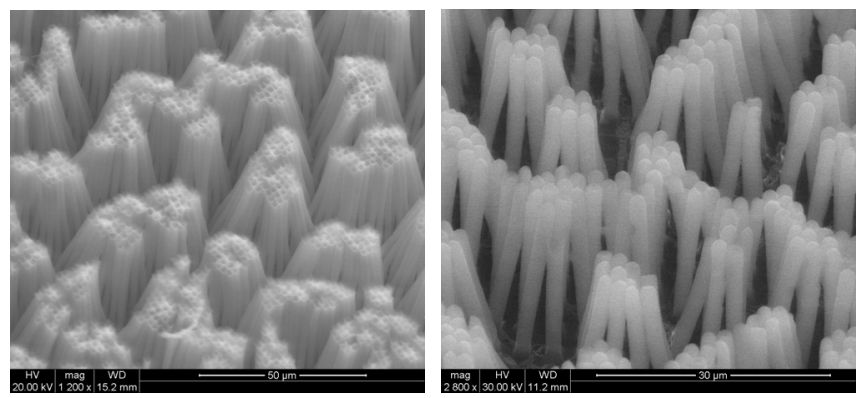

Fig. 6. Environmental Scanning Electron Microscopy (ESEM) images of P3HT microstubes and microfibers respectively after removing template.
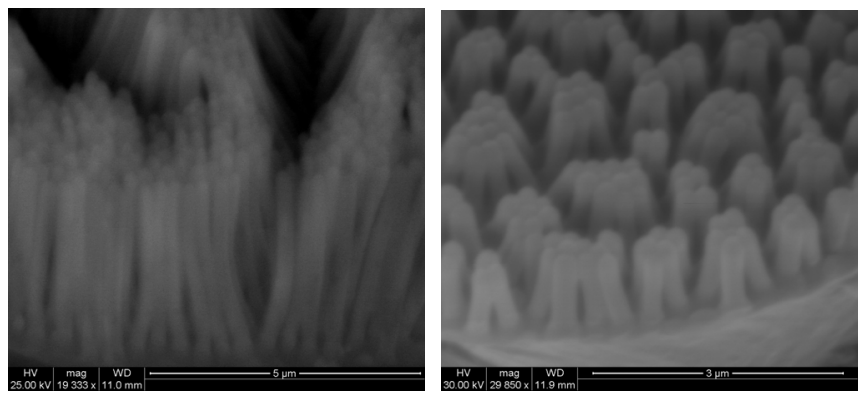

Fig. 7. Environmental Scanning Electron Microscopy (ESEM) images of P3HT nanofibers after removing template.

\section{REFERENCES}

[1] M. Steinhart, J. H. Wendorff, A. Greiner, R. B. Wehrspohn, K. Nielsch, J. Schilling, J. Choi, U. Gösele, Science 296, 1997 (2002).

[2] X. Chen, M. Steinhart, C. Hess, U. Gösele, Adv. Mater. 18, 2153 (2006).

[3] S. Grimm, K. Schwirn, P. Göring, H. Knoll, P. T. Miclea, A. Greiner, J. H. Wendorff, R. B. Wehrspohn, U. Gösele, M. Steinhart, Small 3, 993 (2007).

[4] L. F. Marsal, P. Formentín, R. Palacios, T. Trifonov, J. Ferré-Borrull, A. Rodriguez, J. Pallarés, and R. Alcubilla, Physica Status Solidi (a) 205, 2437 (2008)

[5] R. Palacios, P. Formentín, T. Trifonov, M. Estrada, R. Alcubilla, J. Pallarés, and L. F. Marsal, Physica Status Solidi (RRL) 2, 206 (2008).

[6] R. Palacios, P. Formentín, J. Ferré-Borrull, J. Pallarés, and L. F. Marsal, Physica Status Solidi (c) (Accepted).

[7] C.D.W. Wilkinson, A.S.G. Curtis and J. Crossan, J. Vac. Sci. Technol. B, 16(6), 3132 (1998).

[8] D. C. Olson, J. Piris, R.T. Collins, S.E. Shaheen and D.S. Ginley, Thin Solid Films, 496, 26 (2006).

[9] L. Montelius, B. Heidari, M. Graczyk, I. Maximov, E-L. Sarwe and T.G.I. Ling, Microelectronic Engineering, 53, 521 (2000).

[10] M. Baba, T. Sano, N. Iguchi, K. Iida, T. Sakamoto and H. Kawaura, Applied Physics Letters, 83, 7, 1468 (2003).

[11] a) T.Trifonov, A. Rodríguez, F. Servera, L. F. Marsal, J. Pallarès, R. Alcubilla, Physica Status Solidi (a) 202, 1634 (2005); b) T. Trifonov, M. Garín, A. Rodríguez, L. F. Marsal, R. Alcubilla, Physica Status Solidi (a) 204, 3237 (2007).

[12] A. Santos, L. Vojkuvka, J. Pallarés, J. Ferré-Borrull and L. F. Marsal, Journal of Electroanalytical Chemistry (Submitted). 
Proceedings of the 2009 Spanish Conference on Electron Devices - Feb 11-13, 2009. Santiago de Compostela, Spain.

[13] M. Steinhart, R. B. Wehrspohn, U. Gösele, J. H. Wendorff, Angew. Chem. Int. Ed. 43, 1334 (2004). 